\title{
The Gerbil Elevated Plus-Maze I: Behavioral Characterization and Pharmacological Validation
}

Geoffrey B. Varty, Ph.D., Cynthia A. Morgan, B.Sc., Mary E. Cohen-Williams, B.Sc., Vicki L. Coffin, Ph.D., and Galen J. Carey, Ph.D.

Several neurokinin NK1 receptor antagonists currently being developed for anxiety and depression have reduced affinity for the rat and mouse NK1 receptor compared with human. Consequently, it has proven difficult to test these agents in traditional rat and mouse models of anxiety and depression. This issue has been overcome, in part, by using non-traditional lab species such as the guinea pig and gerbil, which have NK1 receptors closer in homology to human NK1 receptors. However, there are very few reports describing the behavior of gerbils in traditional models of anxiety. The aim of the present study was to determine if the elevated plus-maze, a commonly used anxiety model, could be adapted for the gerbil. Using a specially-designed elevated plus-maze, gerbils exhibited an 'anxious' behavioral profile similar to that observed in rats and mice, i.e., reduced entries into, and time spent exploring, an open, aversive arm. The anxiolytic drugs diazepam $(0.03-3 \mathrm{mg} / \mathrm{kg}$ i.p.), chlordiazepoxide (0.3-10 $\mathrm{mg} / \mathrm{kg}$ i.p.), and buspirone $(0.3-30 \mathrm{mg} / \mathrm{kg}$ s.c.) increased open arm exploration and produced anxiolytic-like effects on risk-assessment behaviors (reduced stretch-attend postures and increased head dips). Of particular interest, the antidepressant drugs imipramine (1-30 mg/kg p.o.), fluoxetine (1-30 mg/kg, p.o.) and paroxetine $(0.3-10 \mathrm{mg} / \mathrm{kg}$ p.o.) each produced some acute anxiolytic-like activity, without affecting locomotor activity. The antipsychotic, haloperidol, and the psychostimulant, amphetamine, did not produce any anxiolytic-like effects (1-10 $\mathrm{mg} / \mathrm{kg}$ s.c). The anxiogenic $\beta$-carboline, FG-7142, reduced time spent in the open arm and head dips, and increased stretch-attend postures (1-30 $m g / k g$, i.p.). These studies have demonstrated that gerbils exhibit an anxiety-like profile on an elevated plus-maze, and that the gerbil elevated plus-maze may have predictive validity for anxiolytics, and antidepressants with potential anxiolytic-like effects.

[Neuropsychopharmacology 27:357-370, 2002]

(C) 2002 American College of Neuropsychopharmacology.

Published by Elsevier Science Inc.
KEY WORDS: Anxiety; Fear; Elevated plus-maze; Gerbil; Anxiolytic drugs; Benzodiazepines; Antidepressant drugs

From the CNS Biological Research, Schering-Plough Research Institute, 2015 Galloping Hill Road, Kenilworth, NJ 07033, USA.

Address correspondence to: Geoffrey Varty, Ph.D., K-15-2-2600 CNS/CV Biological Research, Schering-Plough Research Institute, 2015 Galloping Hill Road, Kenilworth, NJ 07033. Tel: (908) 740-3409; Fax: (908) 740-3294; E-mail: Geoffrey.Varty@SPCorp.com

Received August 3, 2001; revised November 6, 2001; accepted February 8, 2002.

Online publication: 2/22/02 at www.acnp.org/citations/ Npp022202249-1.
Elevated plus-mazes exploit rodents' innate fear of novel, open areas; that is, animals spend significantly less time exploring the open and exposed elevated arm of a maze, compared with the enclosed elevated arm (Pellow et al. 1985; Pellow and File 1986; Lister 1987). These characteristic patterns of behavior have been used extensively to highlight the anti-anxiety effects of both traditional and non-traditional anxiolytic agents (for reviews see Hogg 1996; Rodgers 1997). Generally, animals treated with anxiolytic compounds such as the benzodiazepines (e.g., diazepam, chlordiazepoxide) spend significantly more time exploring the open arms 
compared with vehicle controls (Pellow and File 1986). Furthermore, anxiolytic drugs have also been shown to reduce ethologically based defensive withdrawal behaviors that are commonly exhibited by rodents when they are exposed to potentially threatening situations (Blanchard et al. 1990). Specifically, in the elevated plus-maze, anxiolytic drugs reduce the number of stretch-attend postures (defined as exploration of the open arm with the front part of the body, while the hind region remains in the closed arm, see Cruz et al. (1994)). Further, anxiolytic drugs have also been shown to increase the number of exploratory head dips on the open arms (Griebel et al. 1997; Dalvi and Rodgers 1999; Silva and Brandao 2000). Conversely, known anxiogenic compounds such as the benzodiazepine receptor inverse agonist FG-7142, and pentylenetetrazol, have been shown to produce pro-anxiety, or anxiogenic effects in the mouse and rat elevated plus-mazes, including reduced time spent exploring the open arm and reduced open arm entries (Pellow and File 1986; Lister 1987; Cruz et al. 1994; Cole et al. 1995; Rodgers et al. 1995).

There are pharmacological agents that have reduced affinity for rat and mouse receptors, compared with their human homologs, for example, $5-\mathrm{HT}_{1 \mathrm{D}}$ receptor ligands, adrenergic $\beta 3$ agonists, and neurokinin NK1 receptor antagonists (Beresford et al. 1991; Gitter et al. 1991; Limberger et al. 1991; Bruinvels et al. 1992; Liggett 1992; Arch and Wilson 1996). In these cases, preclinical investigation is most appropriate in species with similar receptor and ligand binding characteristics to human. Of current interest, selective NK1 receptor antagonists are being developed for the treatment of anxiety and depression (Kramer et al. 1998). The majority of these NK1 antagonists have reduced affinity for the rat and mouse NK1 receptor (Beresford et al. 1991; Gitter et al. 1991; Saria 1999), and therefore, preclinical efficacy has been difficult to establish in traditional rodent models of anxiety and depression. There are NK1 antagonists that have comparable affinity at rat and human NK1 receptors and have been tested in traditional models of anxiety and depression. Examples are NKP-608, which has been shown to have anxiolytic-like and antidepressant-like properties in social interaction and chronic mild stress models (File 2000; Papp et al. 2000; Vassout et al. 2000), and FK-888 and WIN51,708, which produced anxiolytic-like effects in mouse and rat elevated plus-mazes, respectively (Teixeira et al. 1996; Nikolaus et al. 1999). Furthermore, research using NK1 receptor knockout mice have shown that the deletion of the NK1 receptor results in a profile of reduced anxietylike behaviors in a number of models including elevated plus-maze, novelty suppressed feeding, and maternal separation-induced vocalizations (Rupniak et al. 2000; Santarelli et al. 2001). However, in general, preclinical research with NK1 antagonists has, by pharmacological necessity, focused on species such as guinea pig and gerbil. These species have NK1 receptors closer in homology to human NK1 receptors, and therefore bind NK1 receptor antagonists with a similar affinity to human (Beresford et al. 1991; Gitter et al. 1991).

Mongolian gerbils (Meriones unguiculatus) are small, easily handled rodents that are used routinely in a hind leg foot-tapping model, a pharmacodynamic assay designed to assess CNS penetration of NK1 antagonists (Graham et al. 1993; Bristow and Young 1994; Rupniak and Williams 1994). However, to date, there are few reports describing the behavior of gerbils in traditional models of anxiety. Early work by Margaret Cutler and colleagues, using gerbils, described the anxiolytic-like effects of selective serotonin $5-\mathrm{HT}_{3}$ receptor antagonists in social interaction and light-dark box assays (Cutler 1990; Cutler and Piper 1990). Of the more recent publications, Ballard et al. (2001) used a fear-conditioning paradigm to demonstrate anxiolytic-like effects of diazepam, and the NK1 antagonists MK-869 and CP-99,994. Additionally, Sandra File and colleagues demonstrated the anxiolytic-like effects of diazepam and the NK1 antagonist L-760,735 in a gerbil social interaction assay (File et al. 2001; Cheeta et al. 2001). Interestingly, the foot-tapping response is an innate behavioral response exhibited when gerbils are exposed to stressful, frightening situations, such as a threat from a predator (Clark and Galef 1982; Ellard et al. 1990; Field and Sibold 1999). Gerbils may use the foot-tapping response to warn of potentially dangerous situations. From personal observations, hind foot tapping can be observed in the laboratory during stressful procedures such as injection or being placed into an aversion environment (see also Clark and Galef 1981). Furthermore, foot tapping can be induced non-pharmacologically using aversive stimuli such as foot shock (Routtenberg and Kramis 1967; Ballard et al. 2001).

The aim of the present study was to expand the development of anxiety models for the gerbil further, by determining whether the elevated plus-maze could be adapted for the gerbil. A specially designed elevated plus-maze was built, testing conditions were optimized, and it was determined that gerbils exhibited an anxiety-like behavioral profile similar to that seen in rats and mice. Following behavioral characterization, the gerbil elevated plus-maze was validated using a range of pharmacologically active compounds. Specifically, the standard anxiolytic drugs, diazepam, chlordiazepoxide, and buspirone, were tested as positive controls, along with the tricyclic antidepressant, imipramine, the selective serotonin reuptake inhibitor (SSRI) antidepressants, fluoxetine, and paroxetine, as well as the antipsychotic, haloperidol, and the psychostimulant, amphetamine. Furthermore, the $\beta$-carboline, FG-7142, was tested for anxiogenic activity. Finally, to address any non-specific effects arising from motoric stimulation, the effects of specific drugs on exploration 
and ambulation were tested using a locomotor activity paradigm. Some of this work has been presented previously in abstract form (Varty et al. 2000).

\section{MATERIALS AND METHODS}

\section{Animals and Housing}

Female Mongolian gerbils (Charles River Laboratories, Kingston, NY) weighing 30-50 g were used for all studies. On arrival at the holding facility, gerbils were housed three per cage, with food and water available ad libitum, in a room maintained under constant temperature $\left(22 \pm 1^{\circ} \mathrm{C}\right)$ and humidity $(50 \%)$. Gerbils were maintained on a $12 \mathrm{~h}$ light/dark cycle (lights on 7:00 A.M.) and all behavioral testing was conducted during the light phase (between the hours of 10 A.M. and 4 P.M.). Gerbils were allowed one week to acclimate to the change in environment before any testing began. Studies were conducted across all phases of the estrous cycle. All studies were carried out in accordance with the National Institute of Health 'Guide for the Care and Use of Laboratory Animals' and were conducted at AAALAC (Association for Assessment and Accreditation of Laboratory Animal Care)-accredited facilities under guidelines established by the Schering-Plough Animal Care and Use Committee.

\section{Gerbil Elevated Plus-Maze}

Testing was carried out on a Plexiglas plus-maze elevated to a height of $35 \mathrm{~cm}$. The apparatus consisted of two open arms $(30 \times 8 \mathrm{~cm})$, and two closed arms of the same dimensions with clear Plexiglas walls $20 \mathrm{~cm}$ high, arranged so that both open and closed arms faced each other. The walls of the closed arms were clear to allow for constant illumination in all parts of the maze. The floor of the maze was constructed of black Plexiglas with $6.5 \mathrm{~mm}$ diameter holes incorporated into the floor, approximately $10 \mathrm{~mm}$ apart. These holes allowed the gerbils to grip the surface, as their movement appeared to be impaired on the slick Plexiglas surfaces traditionally used to construct rat and mouse elevated plus-mazes.

\section{Testing Procedure}

Gerbils were placed into the center area of the maze facing an open arm. An observer, situated approximately $2 \mathrm{~m}$ from the maze, recorded the amount of time each gerbil spent exploring the open and closed arms, and the number of entries into the open and closed arms, for the duration of a 5-min test session. An entry into a specific arm was scored when the gerbil placed all four paws into the arm. Risk-assessment behaviors were also measured. Specifically, the number of head dips on the open arm and the number of protected stretch-attend postures (exploration of the open arm with the front part of the body, while the hind region remains in the closed arm) were recorded. The maze was thoroughly cleaned with dilute soap solution before testing each gerbil.

Initial studies were designed to determine the optimal testing conditions for subsequent drug studies. As light intensity is an important factor when using the elevated plus-maze in rats and mice (Griebel et al. 1993; Hogg 1996), the optimal light level for testing gerbils was first determined. The above behaviors were scored in separate groups of gerbils tested under low light conditions (5-Lux), and high light conditions (500-Lux).

For drug studies, gerbils were administered the drug, and following a specific pretreatment time, the gerbils were placed onto the maze. The observer was blind to the treatment groups and treatments were tested in a counter-balanced, random order. One person observed all the studies, eliminating the need for inter-rater comparison. All studies testing for anxiolytic-like effects were conducted under high light conditions (500-Lux). The drugs tested for anxiolytic-like activity were the benzodiazepines, diazepam $(0.03-3 \mathrm{mg} / \mathrm{kg})$, and chlordiazepoxide $(0.3-10 \mathrm{mg} / \mathrm{kg})$, the serotonin $5-\mathrm{HT}_{1 \mathrm{~A}}$ partial agonist, buspirone $(1-30 \mathrm{mg} / \mathrm{kg})$, the tricyclic antidepressant, imipramine (1-30 mg/kg), the SSRI antidepressants, fluoxetine $(1-30 \mathrm{mg} / \mathrm{kg})$, and paroxetine $(0.3-10 \mathrm{mg} / \mathrm{kg})$, the antipsychotic, haloperidol $(1-10 \mathrm{mg} / \mathrm{kg})$, and the psychostimulant, amphetamine (1-10 mg/kg). The study testing the anxiogenic compound, FG-7142 (1-30 mg/kg), was conducted under low light conditions (5-Lux).

Based on the factor analyses described by Cruz et al. (1994) and Rodgers and Johnson (1995), anxiolytic-like effects were loaded on the behavioral measures of time spent in the open arm (expressed as percentage of total test time), the number of open arm entries (expressed as percentage of total arm entries), the number of stretchattend postures, and the number of open arm head dips. For example, an anxiolytic drug may be expected to have any combination of the following effects: Increased percentage of time spent on the open arm, increased percentage of entries into the open arm, reduced number of stretch-attend postures, and/or increased number of head dips. Effects of locomotion and exploration of the maze were loaded on the number of closed arm entries, that is, a drug that causes sedation and reduces locomotion should reduce the number of closed arm entries, whereas a drug that causes stimulation and increases locomotion should increase the number of closed arm entries.

\section{Measurement of Locomotor Activity in the Gerbil}

Locomotor activity (LMA) was measured using an automated photobeam system (Digiscan, Accuscan Instruments, Columbus, $\mathrm{OH})$. Briefly, gerbils were treated 
with vehicle or a dose of drug, and following an appropriate pretreatment time $(5 \mathrm{~min}$ for amphetamine, 30 min for other drugs), were placed into the corner of one of eight Plexiglas LMA chambers $(42 \times 42 \times 30 \mathrm{~cm}$; $\mathrm{L} \times$ $\mathrm{W} \times \mathrm{H}$ ). Drug doses were balanced across the eight LMA chambers to allow for any differences in sensitivity between the chambers. Horizontal activity was recorded as consecutive breaks in a series of 16 photobeams, spaced $25 \mathrm{~mm}$ apart and $15 \mathrm{~mm}$ above the floor. Horizontal activity (measure of activity detected as breaks in beams) and total distance traveled (measure of ambulation) were recorded by a computer. Activity was measured for a $60 \mathrm{~min}$ test period.

\section{Drugs}

Buspirone hydrochloride and fluoxetine hydrochloride were purchased from Tocris Cookson Inc. (Baldwin, MO). Haloperidol, amphetamine sulfate, diazepam, chlordiazepoxide hydrochloride, and FG-7142 (N-methyl- $\beta$ carboline-3-carboxamide) HBC complex were purchased from RBI/Sigma (Natick, MA). Imipramine and paroxetine were synthesized by the Chemical Research Department at the Schering-Plough Research Institute (Kenilworth, NJ). FG-7142 was administered in distilled water. All other drugs were administered in $0.4 \%$ methylcellulose at a volume of $5-10 \mathrm{ml} / \mathrm{kg}$ (depending on solubility), 30 (chlordiazepoxide, diazepam, buspirone, haloperidol, amphetamine) or 60 (fluoxetine, paroxetine, imipramine) $\mathrm{min}$ before testing in the elevated plus-maze. Drugs were administered via subcutaneous (s.c. - buspirone, haloperidol, amphetamine), intraperitoneal (i.p. - chlordiazepoxide, diazepam, FG-7142), or oral (p.o. - fluoxetine, paroxetine, imipramine) routes. Doses are expressed as free base.

\section{Statistical Analysis}

Data from the study of the 5-Lux and 500-Lux light conditions were directly compared using unpaired $t$-tests. For the elevated plus-maze drug studies, arm time, arm entries, and stretch-attend postures were analyzed using one-way analyses of variance (ANOVA) with drug treatment as a between-subjects factor. The head dips measure was analyzed using a Kruskal-Wallis nonparametric test. In the locomotor activity studies, horizontal activity and total distance traveled data were totaled for the 60 min test and analyzed using one-way ANOVAs with drug treatment as a between-subjects factor. The accepted level of significance for all statistical tests was $p<.05$ and where appropriate, post-hoc analyses were carried out using Dunnett's $t$-test. All statistical analyses were conducted using GraphPad Instat (San Diego, CA).

\section{RESULTS}

\section{Optimization of Testing Conditions}

Gerbils spent significantly more time in the closed arm of the elevated plus-maze under both the low and high light conditions (70\% under the 5-Lux light, $90 \%$ under the 500-Lux). Comparing the 5 and 500-Lux conditions, gerbils spent less time on the open arm under the 500Lux condition (Figure 1, panel A). Percent open arm entries was also reduced under the 500-Lux condition (Figure 1, panel B), but this was not significant. Additionally, gerbils made fewer closed arm entries under the 500-Lux light, and the total number of arm entries was lower at 500-Lux. Furthermore, gerbils made more stretch-attend postures under the 500-Lux condition (Figure 1, panel E). There was no difference in the number of head dips between the light conditions (Figure 1, panel F).

Therefore, the overall behavioral profile exhibited under high level 500-Lux light appeared optimal for detecting anxiolytic-like drug effects as the gerbils spent less time in the open arm, made fewer open arm entries and more stretch-attend postures, thus providing the largest window for measuring anxiolytic-like activity. Interestingly, the 5-Lux light condition produced a behavioral profile suitable for testing anxiogenic drugs, i.e., high level of open arm exploration.

\section{Anxiolytic Drugs}

The benzodiazepines diazepam and chlordiazepoxide increased the percentage of time spent exploring the open arm (Figure 2). Specifically, diazepam produced a dose-related increase in the percentage of time spent on the open $\operatorname{arm}\left(\mathrm{F}_{5,56}=16.2, p<.0001\right)$ with significant effects at $0.3-3 \mathrm{mg} / \mathrm{kg}$ i.p. doses. Diazepam also increased the percentage of open arm entries $\left(\mathrm{F}_{5,56}=2.7, p<.05\right.$, Figure 2), with no change in closed arm entries (see Table 1). This effect of diazepam to selectively increase the percentage of entries into the open arm without affecting closed arm entries is indicative of anxiolytic-like activity. Diazepam (1 and $3 \mathrm{mg} / \mathrm{kg}$ i.p.) increased total arm entries $\left(\mathrm{F}_{5,56}=6.7, p<.0001\right.$, Table 1$)$ and this increase simply reflects the anxiolytic-like effect of diazepam to increase open arm entries.

Chlordiazepoxide produced a significant increase in the percentage of time spent in the open $\operatorname{arm}\left(\mathrm{F}_{4,64}=5.2\right.$, $p<.01)$ at i.p. doses from $0.3-3 \mathrm{mg} / \mathrm{kg}$. Similar to diazepam, chlordiazepoxide also increased percentage of open arm entries $\left(\mathrm{F}_{4,64}=3.0, p<.05\right)$ with significant increases at the 1 and $3 \mathrm{mg} / \mathrm{kg}$ doses. These anxiolyticlike effects of chlordiazepoxide were not confounded by locomotor effects as there was no effect of chlordiazepoxide on closed arm entries. The $10 \mathrm{mg} / \mathrm{kg}$ dose of chlordiazepoxide increased percentage of open arm 
A.

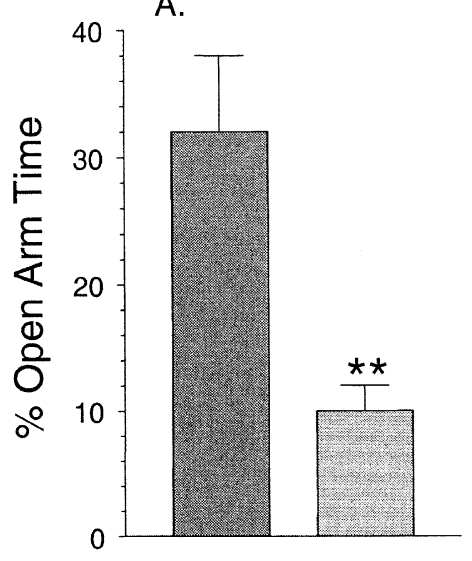

D.

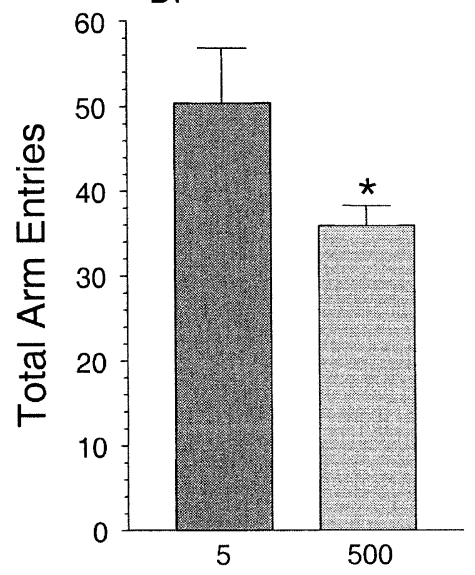

B.

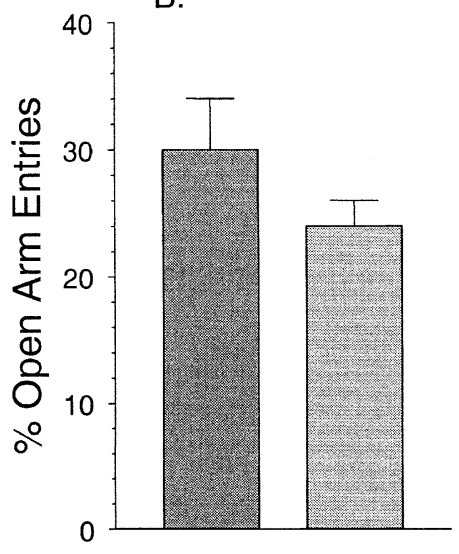

E.

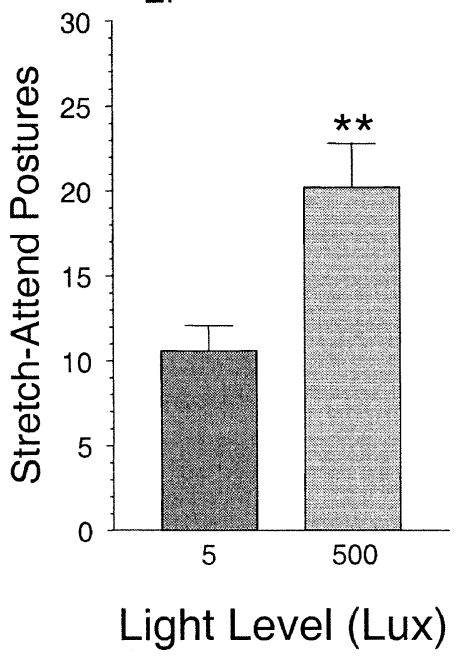

C.

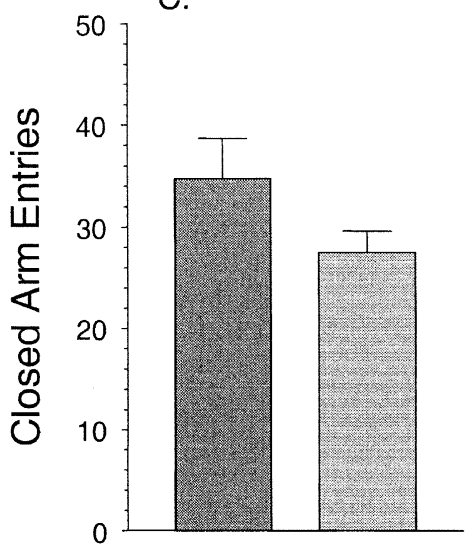

F.

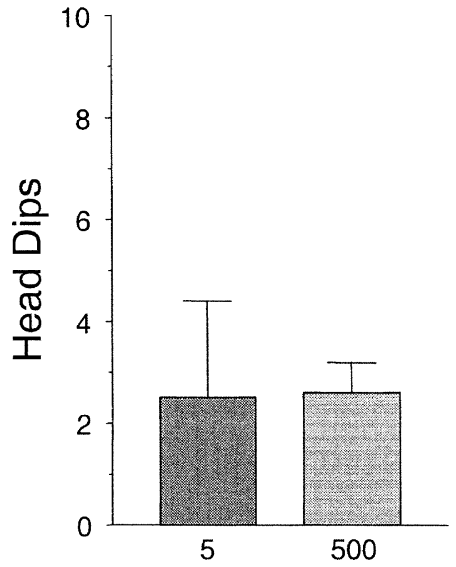

Figure 1. Effects of light intensity on (A) percentage of open arm time, (B) percentage of open arm entries, (C) closed arm entries, (D) total arm entries, (E) stretch-attend postures, and (F) head dips in the gerbil elevated plus-maze. X-axes: Light Intensity (Lux); Y-axes: Behavioral Measures. Values are mean \pm SEM. ${ }^{* *} p<.01,{ }^{*} p<.05$ vs. low light (5 Lux) condition. $\mathrm{n}=10$ per group.

time but the effect was not significant. The reason for the decrease in activity at the $10 \mathrm{mg} / \mathrm{kg}$ dose of chlordiazepoxide is not clear, but it was certainly not due to sedative effects, because there was no decrease in closed or total arm entries at this dose.

Diazepam and chlordiazepoxide also produced anxiolytic-like effects on the ethological measures of anxiety. Diazepam dose-dependently increased the number of head dips $(p<.0001)$, and reduced the number of stretchattend postures $\left(\mathrm{F}_{5,55}=6.3, p<.001\right)$ with significant effects on both measures at i.p. doses of 1 and $3 \mathrm{mg} / \mathrm{kg}$ (Table 1). Chlordiazepoxide reduced stretch-attend postures at i.p. doses of 0.3 and $1 \mathrm{mg} / \mathrm{kg}\left(\mathrm{F}_{4,64}=4.3, p<.01\right)$. Chlordiazepoxide did not increase head dips, and instead there was a significant decrease at the $0.3 \mathrm{mg} / \mathrm{kg}$ dose $(p<.05)$

Buspirone produced a dose-dependent increase in percentage of open arm time $\left(\mathrm{F}_{5,61}=8.4, p<.0001\right)$ and percentage of open arm entries $\left(\mathrm{F}_{5,61}=15.3, p<.0001\right)$. These effects were significant at s.c. doses of 3, 10, and $30 \mathrm{mg} / \mathrm{kg}$ (Figure 2). However, buspirone also reduced the number of open $\left(\mathrm{F}_{5,61}=3.5, p<.01\right)$, closed $\left(\mathrm{F}_{5,61}=\right.$ $8.8, p<.0001)$, and total $\left(\mathrm{F}_{5,61}=8.3, p<.0001\right)$ arm entries (see Table 1). The reductions in closed and total arm entries were significant for the 10 and $30 \mathrm{mg} / \mathrm{kg}$ doses suggesting that these doses may be reducing locomotor activity and exploration. Therefore, only the 3 $\mathrm{mg} / \mathrm{kg}$ dose of buspirone produced an anxiolytic-like effect on percentage of open arm time without reducing indices of exploration and locomotion, i.e. entries into the closed arm. Buspirone reduced stretch-attend postures at the 10 and $30 \mathrm{mg} / \mathrm{kg}$ s.c. doses (Table 1); however, these effects may also reflect the reduced locomotor activity at these doses. There was a trend for the 3 $\mathrm{mg} / \mathrm{kg}$ dose of buspirone to reduce stretch-attend postures and increase head dips (see Table 1). 

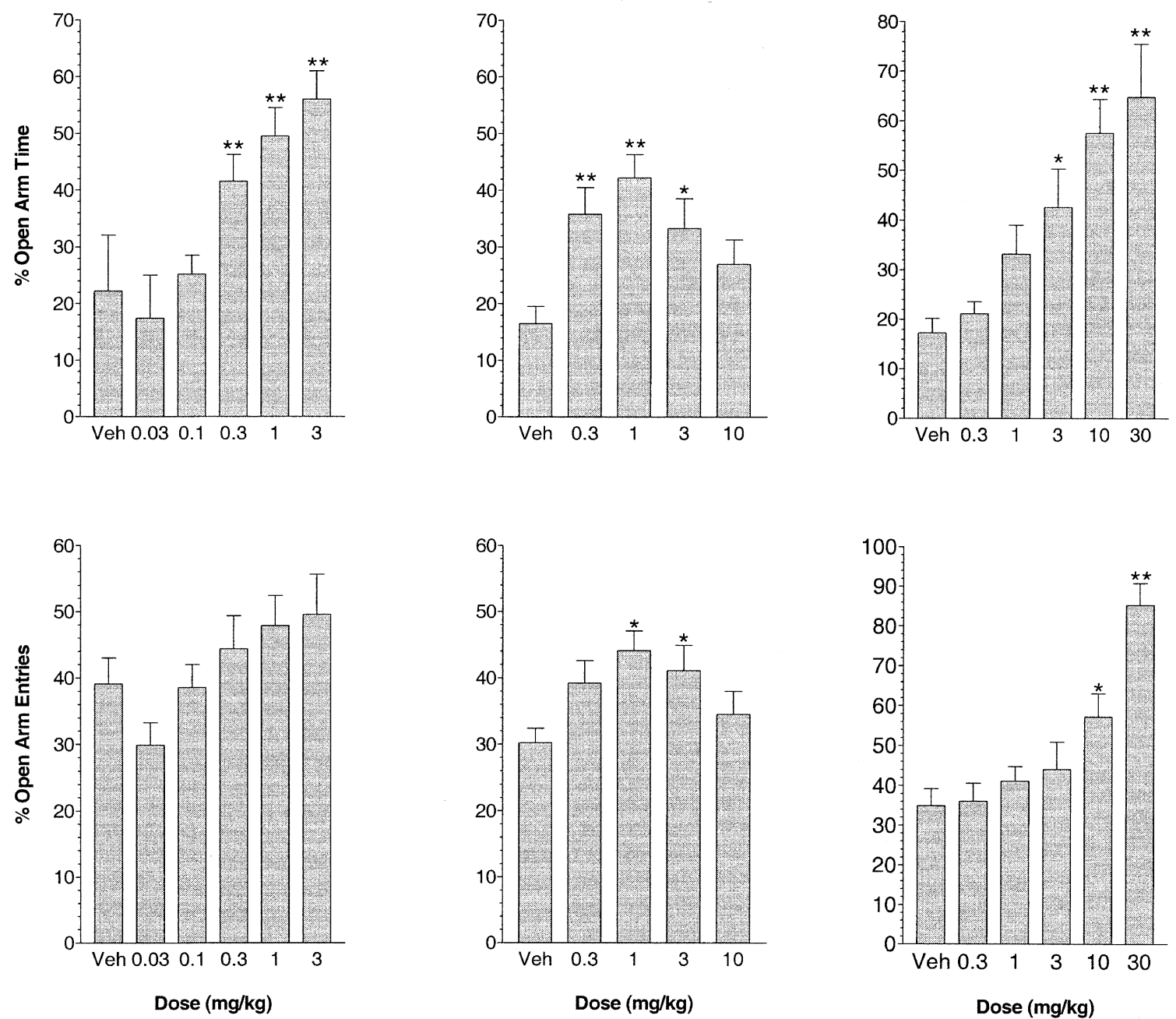

Figure 2. Effects of the anxiolytic drugs diazepam $(0.03-3 \mathrm{mg} / \mathrm{kg}$ i.p.), chlordiazepoxide $(0.3-10 \mathrm{mg} / \mathrm{kg}$ i.p.), and buspirone $(0.3-30 \mathrm{mg} / \mathrm{kg}$ s.c.) on percentage of open arm time and percentage of open arm entries on the gerbil elevated plusmaze. X-axes: Dose (mg/kg); Y-axes: percentage of Open Arm Time (upper panels), percentage of Open Arm Entries (lower panels). Values are mean \pm SEM. ${ }^{* *} p<.01,{ }^{*} p<.05$ vs. vehicle. $\mathrm{n}=9-15$ per dose group.

\section{Antidepressant Drugs}

The tricyclic antidepressant imipramine had no effect on percentage of open arm time (Figure 3), percentage of open arm entries or head dips (Table 2), and increased the total number of arm entries $\left(\mathrm{F}_{4,49}=2.7, p<.05\right)$ with a significant increase at $10 \mathrm{mg} / \mathrm{kg}$ p.o. (Table 2). However, imipramine reduced the number of stretch-attend postures $\left(\mathrm{F}_{4,49}=3.7, p=.01\right)$ with significant anxiolyticlike reductions at the 10 and $30 \mathrm{mg} / \mathrm{kg}$ doses (Table 2). This effect did not appear to be due to motoric effects as there was no change in closed arm entries.

There was a significant overall effect of the SSRI, fluoxetine, to increase the percentage of time in the open $\operatorname{arm}\left(\mathrm{F}_{4,49}=2.8, p<.05\right)$, but no effect on the percentage of open arm entries (Figure 3). Fluoxetine increased closed $\left(\mathrm{F}_{4,49}=5.5, p<.01\right)$ and total $\left(\mathrm{F}_{4,49}=5.4, p<.01\right)$ arm entries (Table 2). Fluoxetine had no effect on stretch-attend postures or head dips.

The SSRI, paroxetine, produced anxiolytic-like effects on a number of measures. Specifically, paroxetine increased percentage of time in the open arm $\left(\mathrm{F}_{4,79}=\right.$ 9.7, $p<.0001)$ and percentage of open arm entries $\left(\mathrm{F}_{4,79}=\right.$ $3.1, p<.05)$, with significant increases at the $10 \mathrm{mg} / \mathrm{kg}$ p.o. dose (Table 2 and Figure 3). Furthermore, paroxetine increased head dips significantly at the 3 and 10 $\mathrm{mg} / \mathrm{kg}$ doses $(p<.0001)$. There was also a trend for paroxetine to reduce stretch-attend postures. Closed arm entries were increased $\left(\mathrm{F}_{4,79}=8.1, p<.0001\right)$, with a significant increase at the $10 \mathrm{mg} / \mathrm{kg}$ dose, and total arm entries were increased $\left(\mathrm{F}_{4,79}=20.7, p<.0001\right)$ at the 1,3 and $10 \mathrm{mg} / \mathrm{kg}$ doses (Table 2). 
Table 1. Effects of the Anxiolytic Drugs Diazepam, Chlordiazepoxide, and Buspirone on Behavioral Measures from the Gerbil Elevated Plus-maze

\begin{tabular}{|c|c|c|c|c|c|c|}
\hline Drug Dose (mg/kg) & $\mathbf{n}$ & $\begin{array}{l}\text { Open Arm } \\
\text { Time (sec) }\end{array}$ & $\begin{array}{l}\text { Closed Arm } \\
\text { Entries }\end{array}$ & $\begin{array}{l}\text { Total Arm } \\
\text { Entries }\end{array}$ & $\begin{array}{l}\text { Stretch-Attend } \\
\text { Postures }\end{array}$ & $\begin{array}{l}\text { Head } \\
\text { Dips }\end{array}$ \\
\hline \multicolumn{7}{|l|}{ Diazepam } \\
\hline Vehicle & 10 & $67 \pm 9$ & $18 \pm 1$ & $30 \pm 3$ & $13 \pm 3$ & $2 \pm 2$ \\
\hline 0.03 & 10 & $52 \pm 7$ & $19 \pm 2$ & $27 \pm 3$ & $21 \pm 3$ & $1 \pm 1$ \\
\hline 0.1 & 10 & $76 \pm 10$ & $19 \pm 2$ & $31 \pm 3$ & $14 \pm 2$ & $1 \pm 1$ \\
\hline 0.3 & 9 & $125 \pm 14^{* *}$ & $22 \pm 2$ & $41 \pm 4$ & $7 \pm 3$ & $6 \pm 2$ \\
\hline 1.0 & 9 & $148 \pm 15^{* *}$ & $23 \pm 4$ & $45 \pm 4^{*}$ & $4 \pm 1^{* *}$ & $11 \pm 3^{* *}$ \\
\hline 3.0 & 9 & $168 \pm 15^{* *}$ & $26 \pm 4$ & $49 \pm 4^{* *}$ & $5 \pm 3^{* *}$ & $14 \pm 4^{* *}$ \\
\hline \multicolumn{7}{|l|}{ Chlordiazepoxide } \\
\hline Vehicle & 15 & $50 \pm 9$ & $21 \pm 2$ & $31 \pm 2$ & $9 \pm 1$ & $4 \pm 1$ \\
\hline 0.3 & 13 & $107 \pm 14^{* *}$ & $20 \pm 2$ & $33 \pm 3$ & $3 \pm 1^{* *}$ & $1 \pm 0.2^{*}$ \\
\hline 1.0 & 13 & $127 \pm 13^{* *}$ & $20 \pm 1$ & $36 \pm 3$ & $3 \pm 1^{* *}$ & $4 \pm 2$ \\
\hline 3.0 & 13 & $100 \pm 16^{*}$ & $19 \pm 1$ & $33 \pm 2$ & $5 \pm 1$ & $4 \pm 1$ \\
\hline 10.0 & 13 & $81 \pm 13$ & $26 \pm 2$ & $41 \pm 3$ & $7 \pm 2$ & $4 \pm 2$ \\
\hline \multicolumn{7}{|l|}{ Buspirone } \\
\hline Vehicle & 12 & $52 \pm 9$ & $16 \pm 2$ & $26 \pm 4$ & $23 \pm 4$ & $3 \pm 1$ \\
\hline 0.3 & 11 & $64 \pm 7$ & $15 \pm 3$ & $22 \pm 4$ & $14 \pm 4$ & $4 \pm 2$ \\
\hline 1.0 & 11 & $99 \pm 18$ & $14 \pm 2$ & $23 \pm 3$ & $17 \pm 3$ & $8 \pm 3$ \\
\hline 3.0 & 11 & $128 \pm 23^{*}$ & $14 \pm 2$ & $26 \pm 4$ & $12 \pm 4$ & $9 \pm 4$ \\
\hline 10.0 & 11 & $173 \pm 21^{* *}$ & $6 \pm 2^{* *}$ & $13 \pm 3^{*}$ & $11 \pm 3^{*}$ & $7 \pm 2$ \\
\hline 30.0 & 11 & $194 \pm 32^{* *}$ & $0.5 \pm 0.2^{* *}$ & $3 \pm 0.4^{* *}$ & $4 \pm 1^{* *}$ & $4 \pm 2$ \\
\hline
\end{tabular}

Values are mean \pm SEM

${ }^{*} p<.05$.

${ }^{* *} p<.01$ vs. vehicle.

\section{Haloperidol and Amphetamine}

Haloperidol and amphetamine had no anxiolytic-like effect in the gerbil elevated plus-maze (Figure 4 and Table 3). Haloperidol dose-dependently reduced percentage of open arm time $\left(\mathrm{F}_{3,36}=10.6, p<.0001\right)$ with significant effects at the 3 and $10 \mathrm{mg} / \mathrm{kg}$ s.c. doses (Figure $4)$. There was a trend for haloperidol to reduce percentage of open arm entries $(p=.07)$. All doses of haloperidol reduced the number of closed arm entries $\left(\mathrm{F}_{3,36}=\right.$ 16.5, $p<.0001)$, and total arm entries $\left(\mathrm{F}_{3,36}=25.8, p<\right.$ $.0001)$. Haloperidol reduced stretch-attend postures at doses of 3 and $10 \mathrm{mg} / \mathrm{kg}\left(\mathrm{F}_{3,36}=10.8, p<.0001\right)$, and reduced head dips at 1,3 , and $10 \mathrm{mg} / \mathrm{kg}$ doses $(p<.01$, Table 3). Collectively, these findings suggest that haloperidol is reducing locomotion and exploration of the maze, probably due to sedating effects.

Amphetamine had no effect on any of the behavioral measures (Table 3 and Figure 4). These doses of amphetamine are known to increase locomotor activity in laboratory animals but there was no evidence of locomotor stimulation on the elevated plus-maze reflected by no obvious increase in the entry measures. At the 10 $\mathrm{mg} / \mathrm{kg}$ s.c. dose of amphetamine, there was in fact a trend for amphetamine to decrease the number of arm entries.

\section{FG-7142}

Under low light conditions, FG-7142 reduced percentage of time in the open arm $\left(\mathrm{F}_{4,50}=4.8, p<.01\right)$ with significant decreases from vehicle at 3-30 mg/kg (Figure 4). There was a trend for a decrease in percentage of open arm entries but this did not reach significance. There was a main effect of FG-7142 on closed arm entries $\left(\mathrm{F}_{4,50}=3.1, p<.05\right)$, with a significant increase at $30 \mathrm{mg} / \mathrm{kg}$. There was no effect on total arm entries. FG7142 increased stretch-attend postures at $30 \mathrm{mg} / \mathrm{kg}$ $\left(\mathrm{F}_{4,50}=4.3, p<.01\right)$, and decreased open arm head dips at doses of 3 and $30 \mathrm{mg} / \mathrm{kg}(p<.05)$.

\section{Locomotor Activity Studies}

Data from the LMA studies are described in Table 4. Amphetamine increased both horizontal activity $\left(\mathrm{F}_{4,25}=\right.$ $8.5, p<.001)$ and total distance traveled $\left(\mathrm{F}_{4,25}=3.7, p<\right.$ $.05)$. Horizontal activity was increased significantly at doses of $1-10 \mathrm{mg} / \mathrm{kg}$, whereas total distance traveled was increased at doses of 3 and $10 \mathrm{mg} / \mathrm{kg}$. Imipramine and fluoxetine had no effect on either measure of locomotor activity. Paroxetine had a significant effect of horizontal activity $\left(\mathrm{F}_{4,25}=5.7, p<.01\right)$; specifically, activity was decreased at 0.3 and $1 \mathrm{mg} / \mathrm{kg}$ doses. There was no effect of paroxetine on total distance traveled.

\section{DISCUSSION}

The purpose of these studies was to adapt a commonly used anxiety paradigm, the elevated plus-maze, for the gerbil. An initial finding was the observation that the elevated plus-maze needed to be adapted to accommo- 
Imipramine
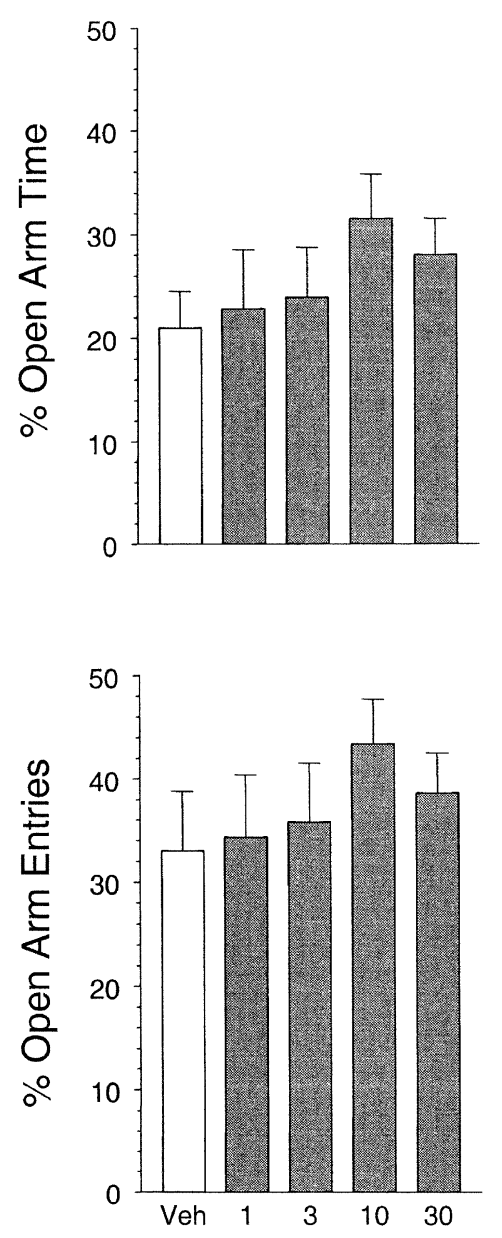

Fluoxetine
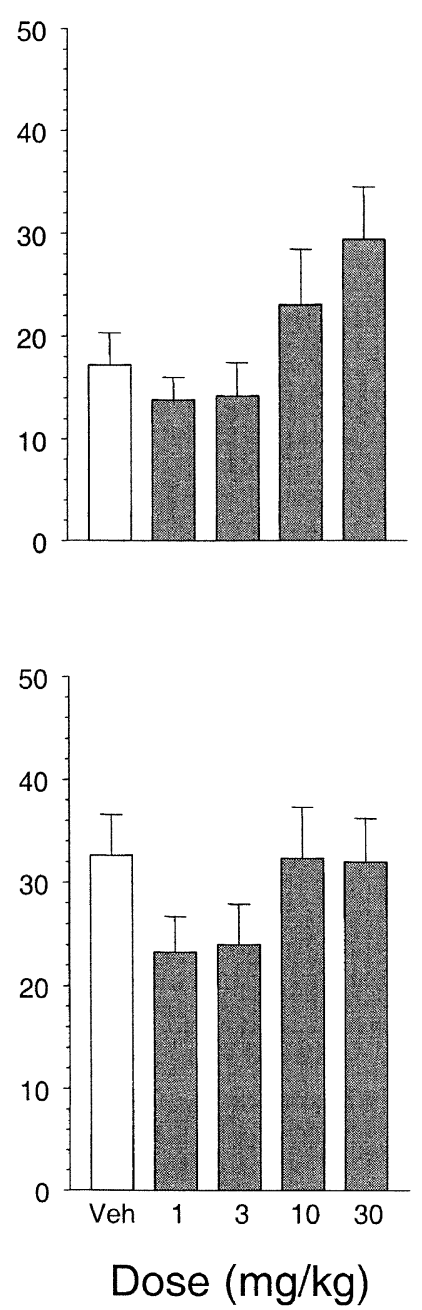

Paroxetine
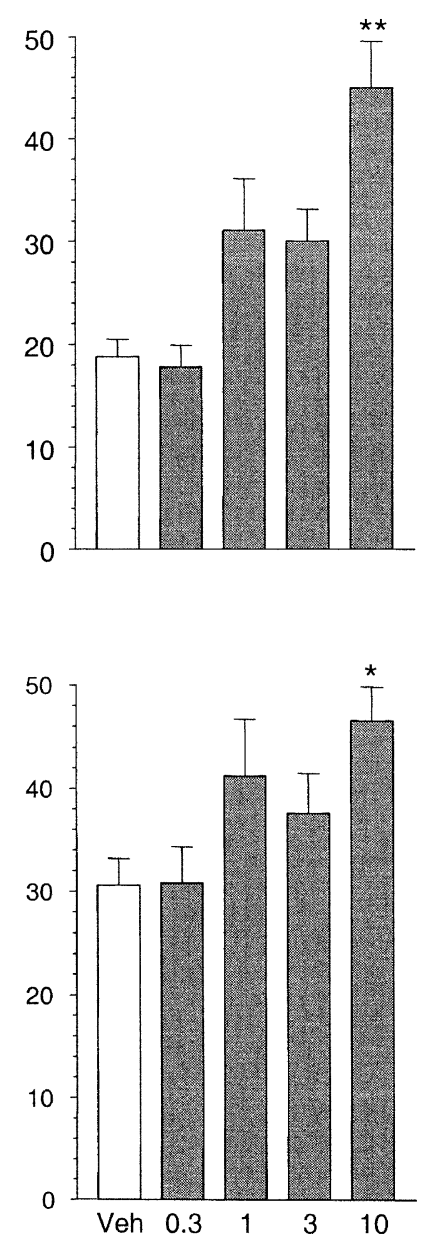

Figure 3. Effects of the antidepressant drugs imipramine (1-30 mg/kg p.o.), fluoxetine (1-30 $\mathrm{mg} / \mathrm{kg}$, p.o.), and paroxetine $(0.3-10 \mathrm{mg} / \mathrm{kg}$ p.o.) on percentage of open arm time and percentage of open arm entries on the gerbil elevated plus-maze. $\mathrm{n}=$ 10-16 per dose group. ${ }^{* *} p<.01,{ }^{*} p<.05$ vs. vehicle.

date the hopping-style locomotion of the gerbil. With this hopping motion, it was clearly difficult for gerbils to maintain adequate traction on the smooth Plexiglas surfaces of rat and mouse elevated plus-mazes. To overcome this problem, a novel plus-maze was constructed with $6.5 \mathrm{~mm}$ diameter holes located $10 \mathrm{~mm}$ apart over the entire surface of the maze.

Using this adapted plus-maze, optimal light conditions of approximately 500-Lux were established for testing gerbils. Based on findings from our lab, the need for high level light in gerbils is similar to rats, but opposite to mice, which typically exhibit an anxiogenic profile under low level light conditions. However, when comparing the baseline data in the gerbil to the published literature in rats and mice, data from the gerbil appeared similar to that reported in the mouse, with comparable amounts of open arm time, open arm entries, closed arm entries, stretch-attend postures, and head dips (see Cruz et al. 1994; Rodgers and Johnson 1995). It is important to reiterate that the present studies used female gerbils. Although the effects of the estrous cycle have not been examined in a specific study, the described studies were conducted during all stages of the estrous cycle and no obvious behavioral effects of estrous were noted. Further studies in male gerbils are warranted to establish whether there is a similar behavioral profile in the elevated plus-maze across both genders.

Interestingly, the low level light produced a behavioral profile in the gerbil that looked appropriate for testing anxiogenic drugs. Typically, it has been difficult to test anxiogenic drugs in the elevated plus-maze due to the low baseline level of open arm exploration (10$20 \%$ open arm time) that is difficult to reduce further. However, the $30-50 \%$ level of exploration in the gerbil under low level lighting appeared to be suitable for 
Table 2. Effects of the Antidepressant Drugs Imipramine, Fluoxetine, and Paroxetine on Behavioral Measures from the Gerbil Elevated Plus-maze

\begin{tabular}{|c|c|c|c|c|c|c|}
\hline Drug Dose $(\mathrm{mg} / \mathrm{kg})$ & $\mathbf{n}$ & $\begin{array}{l}\text { Open Arm } \\
\text { Time (sec) }\end{array}$ & $\begin{array}{l}\text { Closed Arm } \\
\text { Entries }\end{array}$ & $\begin{array}{c}\text { Total Arm } \\
\text { Entries }\end{array}$ & $\begin{array}{l}\text { Stretch-Attend } \\
\text { Postures }\end{array}$ & $\begin{array}{l}\text { Head } \\
\text { Dips }\end{array}$ \\
\hline \multicolumn{7}{|l|}{ Imipramine } \\
\hline Vehicle & 10 & $63 \pm 11$ & $17 \pm 2$ & $27 \pm 3$ & $18 \pm 3$ & $0.7 \pm 0.3$ \\
\hline 1.0 & 10 & $68 \pm 17$ & $18 \pm 2$ & $28 \pm 3$ & $14 \pm 3$ & $0.4 \pm 0.3$ \\
\hline 3.0 & 10 & $71 \pm 14$ & $18 \pm 2$ & $31 \pm 4$ & $13 \pm 2$ & $0.5 \pm 0.5$ \\
\hline 10.0 & 10 & $94 \pm 13$ & $21 \pm 1$ & $40 \pm 5^{*}$ & $8 \pm 2^{*}$ & $2 \pm 1$ \\
\hline 30.0 & 10 & $84 \pm 10$ & $17 \pm 1$ & $28 \pm 2$ & $7 \pm 2^{* *}$ & $3 \pm 1$ \\
\hline \multicolumn{7}{|l|}{ Fluoxetine } \\
\hline Vehicle & 10 & $52 \pm 9$ & $16 \pm 2$ & $24 \pm 3$ & $14 \pm 3$ & $0.6 \pm 0.4$ \\
\hline 1.0 & 10 & $41 \pm 7$ & $22 \pm 2$ & $29 \pm 2$ & $14 \pm 4$ & $1.2 \pm 1.2$ \\
\hline 3.0 & 10 & $43 \pm 9$ & $23 \pm 2$ & $31 \pm 3$ & $13 \pm 1$ & $0.1 \pm 0.1$ \\
\hline 10.0 & 10 & $69 \pm 16$ & $22 \pm 3$ & $35 \pm 5$ & $13 \pm 3$ & $0.7 \pm 0.4$ \\
\hline 30.0 & 10 & $88 \pm 15$ & $30 \pm 3^{* *}$ & $45 \pm 3^{* *}$ & $17 \pm 4$ & $0.3 \pm 0.2$ \\
\hline \multicolumn{7}{|l|}{ Paroxetine } \\
\hline Vehicle & 16 & $56 \pm 5$ & $17 \pm 1$ & $25 \pm 1$ & $20 \pm 2$ & $0.7 \pm 0.4$ \\
\hline 0.3 & 16 & $53 \pm 6$ & $19 \pm 2$ & $28 \pm 2$ & $17 \pm 2$ & $0.6 \pm 0.6$ \\
\hline 1.0 & 16 & $93 \pm 15$ & $22 \pm 3$ & $37 \pm 3^{*}$ & $15 \pm 3$ & $3 \pm 2$ \\
\hline 3.0 & 16 & $90 \pm 9$ & $23 \pm 2$ & $39 \pm 4^{* *}$ & $17 \pm 3$ & $4 \pm 1^{* *}$ \\
\hline 10.0 & 16 & $135 \pm 14^{* *}$ & $32 \pm 2^{* *}$ & $61 \pm 3^{* *}$ & $14 \pm 3$ & $6 \pm 2^{* *}$ \\
\hline
\end{tabular}

Values are mean \pm SEM

$* p<.05$.

$* * p<.01$ vs. vehicle.

testing anxiogenic drugs. To test this hypothesis, the anxiogenic, $\beta$-carboline, FG-7142, was administered to gerbils under the 5-Lux light condition. FG-7142 produced a behavioral profile consistent with anxiogenesis (i.e., reduced percentage of open arm time and open arm entries, increased stretch-attend postures, and reduced open arm head dips). These findings are in accordance with the published effects of FG-7142 in rat and mouse elevated plus-mazes (Pellow and File 1986;
Lister 1987; Cruz et al. 1994; Cole et al. 1995; Rodgers et al. 1995).

The main aim of these studies was to pharmacologically validate the gerbil elevated plus-maze by testing standard anxiolytic drugs such as the benzodiazepines and $5-\mathrm{HT}_{1 \mathrm{~A}}$ partial agonists, as well as antidepressants, a stimulant and an antipsychotic drug. The benzodiazepines, diazepam and chlordiazepoxide, and the $5-\mathrm{HT}_{1 \mathrm{~A}}$ partial agonist, buspirone, produced anxiolytic-like

Table 3. Effects of the Antipsychotic Haloperidol, the Psychostimulant Amphetamine, and the Benzodiazepine Receptor Inverse Agonist FG-7142, on Behavioral Measures from the Gerbil Elevated Plus-maze

\begin{tabular}{|c|c|c|c|c|c|c|}
\hline Drug Dose (mg/kg) & $\mathbf{n}$ & $\begin{array}{l}\text { Open Arm } \\
\text { Time (sec) }\end{array}$ & $\begin{array}{l}\text { Closed Arm } \\
\text { Entries }\end{array}$ & $\begin{array}{l}\text { Total Arm } \\
\text { Entries }\end{array}$ & $\begin{array}{l}\text { Stretch-Attend } \\
\text { Postures }\end{array}$ & $\begin{array}{l}\text { Head } \\
\text { Dips }\end{array}$ \\
\hline \multicolumn{7}{|l|}{ Haloperidol } \\
\hline Vehicle & 10 & $58 \pm 8$ & $15 \pm 3$ & $24 \pm 4$ & $16 \pm 3$ & $2.6 \pm 1$ \\
\hline 1.0 & 10 & $32 \pm 12$ & $6 \pm 1.4^{* *}$ & $7.4 \pm 1.5^{* *}$ & $11 \pm 2$ & $1 \pm 1^{*}$ \\
\hline 3.0 & 10 & $9 \pm 6^{* *}$ & $3 \pm 0.6^{* *}$ & $3.6 \pm 0.6^{* *}$ & $4 \pm 2^{* *}$ & $0 \pm 0^{* *}$ \\
\hline 10.0 & 10 & $2 \pm 1^{* *}$ & $1.6 \pm 0.5^{* *}$ & $2 \pm 0.5^{* *}$ & $2 \pm 0.5^{* *}$ & $0 \pm 0^{* *}$ \\
\hline \multicolumn{7}{|l|}{ Amphetamine } \\
\hline Vehicle & 10 & $68 \pm 9$ & $15 \pm 3$ & $24 \pm 4$ & $16 \pm 3$ & $3 \pm 1$ \\
\hline 1.0 & 10 & $42 \pm 11$ & $20 \pm 3$ & $28 \pm 4$ & $19 \pm 3$ & $1.3 \pm 0.7$ \\
\hline 3.0 & 10 & $58 \pm 14$ & $17 \pm 3$ & $27 \pm 5$ & $15 \pm 3$ & $1.5 \pm 1$ \\
\hline 10.0 & 10 & $58 \pm 26$ & $12 \pm 2$ & $17 \pm 3$ & $13 \pm 4$ & $0.1 \pm 0.1$ \\
\hline \multicolumn{7}{|l|}{ FG-7142" } \\
\hline Vehicle & 15 & $129 \pm 14$ & $17 \pm 2$ & $32 \pm 2$ & $8 \pm 2$ & $5.6 \pm 1.7$ \\
\hline 1.0 & 10 & $114 \pm 12$ & $18 \pm 2$ & $32 \pm 2$ & $7 \pm 2$ & $1.9 \pm 0.9$ \\
\hline 3.0 & 10 & $80 \pm 12^{*}$ & $17 \pm 2$ & $27 \pm 2$ & $13 \pm 2$ & $1.0 \pm 1.0^{*}$ \\
\hline 10.0 & 10 & $79 \pm 8^{*}$ & $21 \pm 1$ & $33 \pm 2$ & $14 \pm 2$ & $0.6 \pm 0.3^{*}$ \\
\hline 30.0 & 10 & $71 \pm 11^{* *}$ & $23 \pm 1^{*}$ & $37 \pm 2$ & $19 \pm 2^{* *}$ & $0.1 \pm 0.1^{* *}$ \\
\hline
\end{tabular}

Values are mean \pm SEM

${ }^{*} p<.05 ;{ }^{* *} p<.01$ vs. vehicle

"Tested under low light conditions of 5 Lux 
Haloperidol
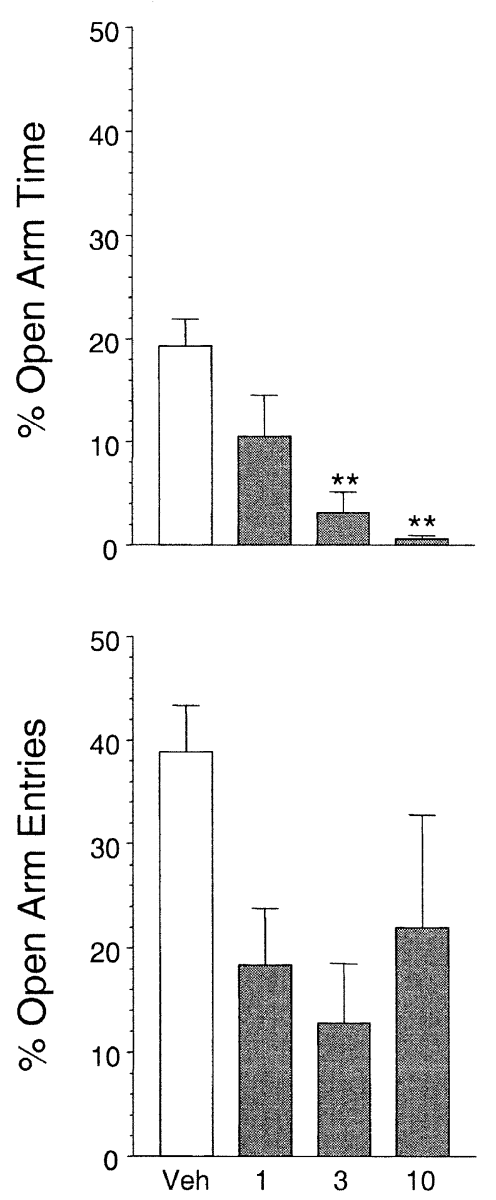

Amphetamine
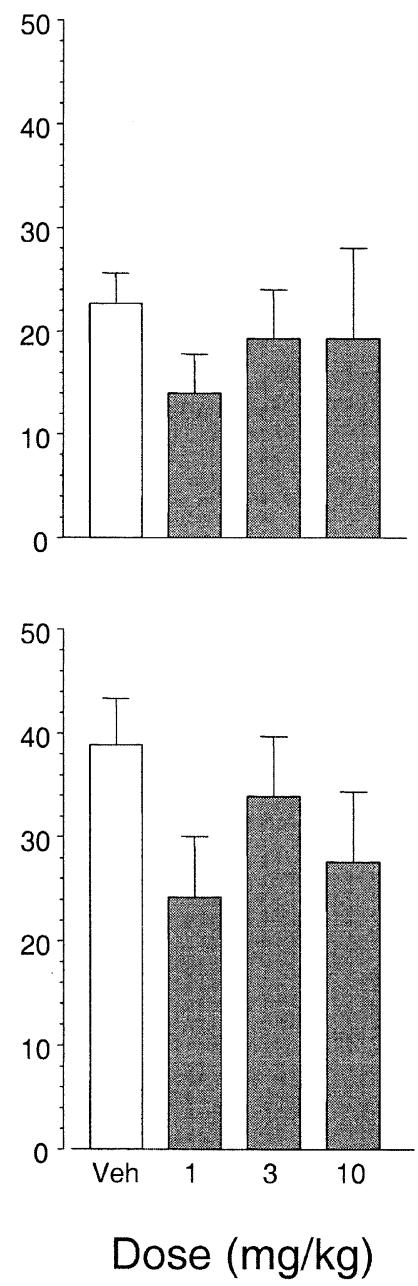

FG-7142
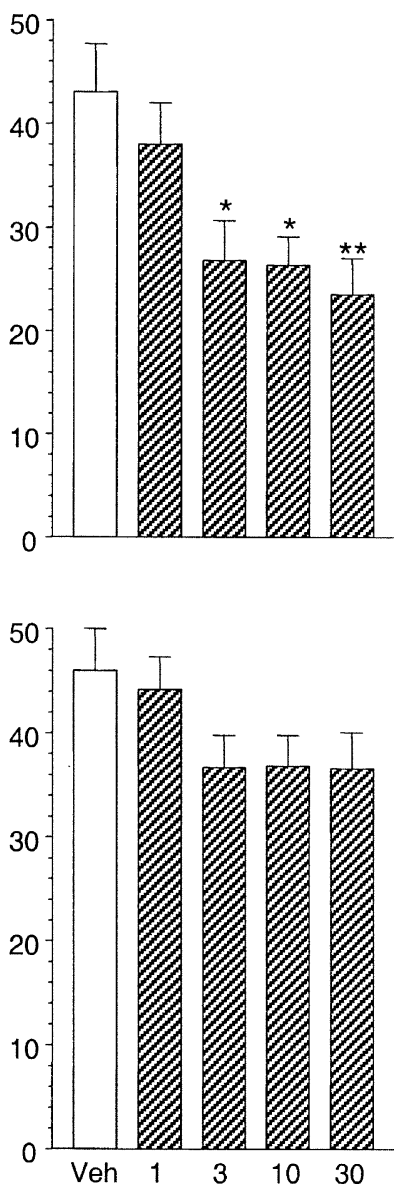

Figure 4. Effects of the antipsychotic haloperidol (1-10 mg/kg s.c), the psychostimulant amphetamine (1-10 mg/kg s.c), and the benzodiazepine inverse agonist FG-7142 (1-30 mg/kg, i.p.) on percentage of open arm time and percentage of open arm entries on the gerbil elevated plus-maze. $\mathrm{n}=10-15$ per dose group. Please note higher level of percentage of open arm time in the FG-7142 study due to testing gerbils under low light conditions (5-Lux). ${ }^{* *} p<.01,{ }^{*} p<.05$ vs. vehicle.

activity across a number of measures. However, the anxiolytic-like effects of buspirone at doses of 10 and 30 $\mathrm{mg} / \mathrm{kg}$ were also accompanied by effects on locomotion, making interpretation of the data difficult, and suggesting that the effects of the 10 and $30 \mathrm{mg} / \mathrm{kg}$ doses of buspirone on the anxiolytic measures may be due to sedation, rather than anxiolysis (see Cole and Rodgers 1994). However, the $3 \mathrm{mg} / \mathrm{kg}$ dose appeared to selectively increase percentage of open arm time without affecting locomotion, suggesting that, at least in the gerbil, this is an anxiolytic-like dose. These complex findings with buspirone are in accordance with the rat and mouse elevated plus-maze literature, that describes either anxiogenic-like, anxiolytic-like, and/or sedative effects following buspirone treatment (Pellow and File 1986; Moser 1989; Lee and Rodgers 1991; Cole and Rodgers 1994; Cao and Rodgers 1997; Collinson and Dawson 1997). Overall, the gerbil elevated plusmaze appeared to have good predictive validity for detecting the anxiolytic-like effects of the benzodiazepine class of drugs. This preliminary study also suggests that the model may be sensitive to the anxiolytic-like effects of $5-\mathrm{HT}_{1 \mathrm{~A}}$ agonists, although this class of compound produced a different behavioral profile than the benzodiazepines. In particular, there appeared to be a narrow efficacious window with buspirone, compared with the benzodiazepines, in terms of anxiolytic versus sedative effects.

Currently, clinical anxiety disorders are being increasingly treated with agents that are traditionally considered as antidepressants, e.g., fluoxetine and paroxetine (Schatzberg 2000; Zohar and Westenberg 2000), 
Table 4. Effects of Amphetamine, Imipramine, Fluoxetine, and Paroxetine on Spontaneous Locomotor Activity in the Gerbil

\begin{tabular}{lcc}
\hline Drug & $\begin{array}{c}\text { Horizontal Activity } \\
\text { (counts) }\end{array}$ & $\begin{array}{c}\text { Total Distance } \\
\text { (cm) }\end{array}$ \\
\hline $\begin{array}{c}\text { Amphetamine } \\
\text { Vehicle }\end{array}$ & $7841 \pm 634$ & \\
$0.3 \mathrm{mg} / \mathrm{kg}$ & $9726 \pm 1049$ & $1889 \pm 234$ \\
$1 \mathrm{mg} / \mathrm{kg}$ & $14717 \pm 2147^{*}$ & $2429 \pm 400$ \\
$3 \mathrm{mg} / \mathrm{kg}$ & $18279 \pm 1265^{* *}$ & $4680 \pm 953$ \\
$10 \mathrm{mg} / \mathrm{kg}$ & $15540 \pm 1784^{* *}$ & $5708 \pm 522^{*}$ \\
Imipramine & & \\
Vehicle & $7841 \pm 634$ & $1889 \pm 234$ \\
$1 \mathrm{mg} / \mathrm{kg}$ & $6090 \pm 340$ & $1369 \pm 106$ \\
$3 \mathrm{mg} / \mathrm{kg}$ & $5921 \pm 547$ & $1287 \pm 207$ \\
$10 \mathrm{mg} / \mathrm{kg}$ & $7442 \pm 1125$ & $1913 \pm 449$ \\
$30 \mathrm{mg} / \mathrm{kg}$ & $6458 \pm 481$ & $1580 \pm 94$ \\
Fluoxetine & & \\
Vehicle & $7217 \pm 1088$ & $1754 \pm 358$ \\
$1 \mathrm{mg} / \mathrm{kg}$ & $6790 \pm 977$ & $1636 \pm 246$ \\
$3 \mathrm{mg} / \mathrm{kg}$ & $7462 \pm 442$ & $1708 \pm 144$ \\
$10 \mathrm{mg} / \mathrm{kg}$ & $7346 \pm 538$ & $1693 \pm 238$ \\
$30 \mathrm{mg} / \mathrm{kg}$ & $8861 \pm 1072$ & $2428 \pm 574$ \\
Paroxetine & & \\
Vehicle & $9192 \pm 596$ & $2131 \pm 183$ \\
$0.3 \mathrm{mg} / \mathrm{kg}$ & $6426 \pm 582^{*}$ & $1435 \pm 130$ \\
$1 \mathrm{mg} / \mathrm{kg}$ & $5946 \pm 437^{* *}$ & $1399 \pm 203$ \\
$3 \mathrm{mg} / \mathrm{kg}$ & $8707 \pm 1053$ & $2098 \pm 374$ \\
$10 \mathrm{mg} / \mathrm{kg}$ & $9089 \pm 383$ & $2561 \pm 137$ \\
\hline
\end{tabular}

Values are mean \pm SEM

${ }^{*} p<.05$.

${ }^{* *} p<.01$ vs. vehicle.

despite these agents having limited anxiolytic-like activity in preclinical models, especially rat and mouse elevated plus-mazes. It is therefore important to identify animal models and/or species that more accurately predict the clinical efficacy of non-traditional anxiolytic agents such as the SSRI antidepressants. In these studies, we tested the tricyclic antidepressant, imipramine, and the SSRIs, fluoxetine and paroxetine, in gerbils to assess their behavioral effects following acute administration. Interestingly, all three antidepressant drugs produced some acute anxiolytic-like effects, albeit to different magnitudes. Imipramine reduced the number of stretch-attend postures, while fluoxetine and paroxetine increased the percentage of time spent exploring the open arm. The three antidepressants did not reduce closed arm entries, suggesting that there were no sedating effects. In fact, the three compounds actually appeared to increase the total number of entries into all arms of the maze suggesting, if anything, a possible simulating effect, and a profile different to the benzodiazepines and buspirone. However, this stimulant-like profile with the antidepressants appeared different from a general psychostimulant effect, because amphetamine, at behaviorally activating doses, did not increase arm entries in these studies. To further clarify these findings, imipramine, fluoxetine, and paroxetine were tested in a gerbil locomotor activity (LMA) paradigm for effects on spontaneous locomotion, and compared with amphetamine, which is known to stimulate locomotor activity in rats and mice (Taylor and Snyder 1970; Glick 1972; Creese and Iverson 1973). The dose ranges tested were identical to those tested in the elevated plus-maze studies. In contrast to amphetamine, that produced a marked increase in LMA, the antidepressant drugs did not increase LMA at doses that were clearly anxiolytic in the elevated-plus maze. These data suggest that the anxiolytic-like effects of these doses of the antidepressant drugs were not due to locomotor stimulation.

Interestingly, the anxiolytic-like profile of the tricyclic antidepressant, imipramine, was different to the profile of the SSRIs, fluoxetine and paroxetine. Imipramine had no effect on the open arm time and entry measures, and specifically reduced stretch-attend postures. Conversely, the SSRIs increased open arm time and entries and had no effect of stretch-attend postures. These effects may suggest some mechanistic difference in the anxiolytic-like properties of tricyclic antidepressants, compared with the SSRIs, but further studies examining the effects of other tricyclic and SSRI antidepressants are warranted to expand the present findings. Furthermore, future studies should also examine other classes of antidepressants, including the monoamine oxidase inhibitors (MAOIs), and serotonin and norepinepherine reuptake inhibitors (SNRIs), to determine, first, whether these classes are anxiolytic-like in the gerbil elevated plus-maze, and second, how any such anxiolytic-like activity compares to the tricyclic and SSRI antidepressants.

Of the three antidepressant drugs studied in the present experiments, paroxetine produced the strongest anxiolytic-like effect with increases in open arm exploration, open arm entries, and head dips. Furthermore, paroxetine appeared the most potent with anxiolyticlike effects at a $10 \mathrm{mg} / \mathrm{kg}$ dose, rather than the $30 \mathrm{mg} /$ $\mathrm{kg}$ doses of imipramine and fluoxetine. Recently, paroxetine has been approved for the treatment of social phobia (Schatzberg 2000; Zohar and Westenberg 2000) and is currently in clinical trials for the treatment of Generalized Anxiety Disorder (GAD). The data in the present study support the potential anti-anxiety effects of paroxetine by demonstrating the acute anxiolyticlike effects of the drug in an elevated plus-maze that exploits neophobia in animals.

It is important to note that previous studies in rat and mouse elevated plus-mazes have not demonstrated any acute anxiolytic-like effects of antidepressant drugs. For example, Griebel et al. (1997), Lister (1987), and Cole and Rodgers (1994) all reported that imipramine was inactive in rat and mouse elevated plus-maze. Similarly, fluoxetine and paroxetine did not exhibit any anxiolyticlike activity in rat and mouse elevated plus-maze, and 
in fact produced anxiogenic effects (Silva et al. 1999; Kurt et al. 2000; Silva and Brandao 2000; Koks et al. 2001). However, in contrast to the data generated in rat and mouse elevated plus-mazes, imipramine, fluoxetine, and paroxetine have been shown to produce anxiolytic-like actions in a number of other animal models of anxiety, including rat social interaction (Lightowler et al. 1994), shock- or separation-induced vocalizations in rats and guinea pigs (Molewijk et al. 1995; Molewijk et al. 1996; Kramer et al. 1998; Schreiber et al. 1998; Podhorna and Brown 2000), and the four-plate test in mice (Hascoet et al. 2000). Therefore, it is of interest that the gerbil elevated plus-maze appears to corroborate the anxiolytic findings with antidepressants in other invivo anxiety models and the recent findings in human patients. The gerbil elevated plus-maze may therefore be a valuable alternative to the traditional rat and mouse elevated plus-mazes for examining the potential anxiolytic-like properties of novel antidepressant agents.

Of final note, the clinical anxiolytic actions of antidepressant drugs only become apparent following a period of chronic administration. However, while the effects of chronic administration of imipramine, fluoxetine, and paroxetine were beyond the scope of the present studies, those experiments are certainly warranted to determine if chronic antidepressant treatment can produce a similar, reduced, or enhanced anxiolyticlike effect in the gerbil elevated plus-maze.

In further validation studies, the dopamine $\mathrm{D}_{2}$ antagonist and antipsychotic, haloperidol, and the indirect dopamine agonist and psychostimulant, amphetamine, had no effect in the gerbil elevated plus-maze. At high doses, haloperidol produced a behavioral profile consistent with sedation (see Cole and Rodgers 1994). Surprisingly, despite using doses that stimulated locomotion in the gerbil, amphetamine did not appear to increase overall exploration or locomotion in the elevated plus-maze. In fact, the $10 \mathrm{mg} / \mathrm{kg}$ dose of amphetamine appeared to reduce entries, which may have been due to the appearance of stereotyped behavior(s), or the known anxiogenic effects of amphetamine (Pellow et al. 1985; Lister 1987; Lapin 1993).

The main aim of these studies was to determine if the elevated plus-maze could be adapted for the gerbil, and whether the paradigm had predictive validity for detecting anxiolytic drugs. These studies demonstrated that the gerbil displays an anxiety-like behavioral profile similar to rats and mice under specific light conditions. Furthermore, the gerbil elevated plus-maze was sensitive to the anxiolytic effects of benzodiazepines and the $5-\mathrm{HT}_{1 \mathrm{~A}}$ partial agonist buspirone. Interestingly, the gerbil elevated plus-maze also detected some anxiolytic-like effects following acute administration of selected antidepressant drugs, particularly with the SSRI paroxetine, which is currently prescribed for the treat- ment of social phobia. Finally, when tested under appropriate conditions, the gerbil elevated plus-maze was also sensitive to the anxiogenic effects of the benzodiazepine receptor inverse agonist, FG-7142. In summary, the gerbil elevated plus-maze appears to be a valid model of anxiety and neophobia for detecting anxiolytic and anxiogenic drugs, similar to other anxiety models in gerbils (Ballard et al. 2001; File et al. 2001). Furthermore, the gerbil elevated plus-maze may be beneficial as a means to assay the anxiolytic-like effects of pharmacological classes that exhibit a reduced affinity for rat and mouse receptors, such as the neurokinin NK1 receptor antagonists.

\section{ACKNOWLEDGMENTS}

The authors would like to thank Drs. Lisa Gold and John Hunter for their helpful comments and Roland Parker for his excellent craftsmanship in constructing the gerbil elevated plus-maze.

\section{REFERENCES}

Arch JR, Wilson S (1996): Prospects for beta 3-adrenoceptor agonists in the treatment of obesity and diabetes. Int J Obes Relat Metab Disord 20:191-199

Ballard TM, Sanger S, Higgins GA (2001): Inhibition of shock-induced foot tapping behaviour in the gerbil by a tachykinin NK(1) receptor antagonist. Eur J Pharmacol 412:255-264

Beresford IJ, Birch PJ, Hagan RM, Ireland SJ (1991): Investigation into species variants in tachykinin NK1 receptors by use of the non-peptide antagonist, CP-96,345. Br J Pharmacol 104:292-293

Blanchard RJ, Blanchard DC, Weiss SM, Meyer S (1990): The effects of ethanol and diazepam on reactions to predatory odors. Pharmacol Biochem Behav 35:775-780

Bristow LJ, Young L (1994): Chromodacryorrhea and repetitive hind paw tapping: models of peripheral and central tachykinin NK1 receptor activation in gerbils. Eur J Pharmacol 253:245-252

Bruinvels AT, Lery H, Nozulak J, Palacios JM, Hoyer D (1992): 5-HT1D binding sites in various species: similar pharmacological profile in dog, monkey, calf, guineapig and human brain membranes. Naunyn Schmiedebergs Arch Pharmacol 346:243-248

Cao BJ, Rodgers RJ (1997): Comparative behavioural profiles of buspirone and its metabolite 1-(2-pyrimidinyl)-piperazine $(1-P P)$ in the murine elevated plus-maze. Neuropharmacology 36:1089-1097

Cheeta S, Tucci S, Sandhu J, Williams AR, Rupniak NMJ, File SE (2001): Anxiolytic actions of the Substance P $\left(\mathrm{NK}_{1}\right)$ receptor antagonist $\mathrm{L}-760,735$ and the $5-\mathrm{HT}_{1 \mathrm{~A}}$ agonist, 8-OH-DPAT in the social interaction test in gerbils. Brain Res 915:170-175

Clark MM, Galef BG Jr (1981): Environmental influence on development, behavior, and endocrine morphology of gerbils. Physiol Behav 27:761-765 
Clark MM, Galef BG Jr (1982): Environmental effects on the ontogeny of exploratory and escape behaviors of Mongolian gerbils. Devel Psychobiol 15:121-129

Cole BJ, Hillmann M, Seidelmann D, Klewer M, Jones GH (1995): Effects of benzodiazepine receptor partial inverse agonists in the elevated plus maze test of anxiety in the rat. Psychopharmacology (Berl) 121:118-126

Cole JC, Rodgers RJ (1994): Ethological evaluation of the effects of acute and chronic buspirone treatment in the murine elevated plus-maze test: comparison with haloperidol. Psychopharmacology (Berl) 114:288-296

Collinson N, Dawson GR (1997): On the elevated plus-maze the anxiolytic-like effects of the 5-HT(1A) agonist, $8-\mathrm{OH}$ DPAT, but not the anxiogenic-like effects of the 5-HT(1A) partial agonist, buspirone, are blocked by the 5-HT1A antagonist, WAY 100635. Psychopharmacology (Berl) 132:35-43

Creese I, Iverson SD (1973): Blockage of amphetamine induced motor stimulation and stereotypy in the adult rat following neonatal treatment with 6-hydroxydopamine. Brain Res 55:369-382

Cruz AP, Frei F, Graeff FG (1994): Ethopharmacological analysis of rat behavior on the elevated plus-maze. Pharmacol Biochem Behav 49:171-176

Cutler MG (1990): Behavioral effects in gerbils of the 5-HT3 receptor antagonists, BRL 43694 and ICS 205-930, under circumstances of high and low light intensity. Neuropharmacology 29:515-520

Cutler MG, Piper DC (1990): Chronic administration of the 5-HT3 receptor antagonist BRL 43694; effects on reflex epilepsy and social behaviour of the Mongolian gerbil. Psychopharmacology (Berl) 101:244-249

Dalvi A, Rodgers RJ (1999): Behavioral effects of diazepam in the murine plus-maze: flumazenil antagonism of enhanced head dipping but not the disinhibition of openarm avoidance. Pharmacol Biochem Behav 62:727-734

Ellard CG, Stewart DJ, Donaghy S, Vanderwolf CH (1990): Behavioral effects of neocortical and cingulate lesions in the Mongolian gerbil. Behav Brain Res 36:41-51

Field KJ, Sibold AL (1999): The Laboratory Hamster \& Gerbil (Ed. M. Suckow). Boca Raton, FL, CRC Press

File SE (2000): NKP608, an NK1 receptor antagonist, has an anxiolytic action in the social interaction test in rats. Psychopharmacology (Berl) 152:105-109

File SE, Cheeta S, Akanezi C (2001): Diazepam and nicotine increase social interaction in gerbils: a test for anxiolytic action. Brain Res 888:311-313

Gitter BD, Waters DC, Bruns RF, Mason NR, Nixon JA, Howbert JJ (1991): Species differences in affinities of non-peptide antagonists for substance P receptors. Eur J Pharmacol 197:237-238

Glick SD (1972): Changes in amphetamine sensitivity following frontal cortical damage in rats and mice. Eur J Pharmacol 20:351-356

Graham EA, Turpin MP, Stubbs CM (1993): Characterisation of the tachykinin-induced hindlimb thumping response in gerbils. Neuropeptides 4:228

Griebel G, Moreau G-L, Jenck F, Martin JR, Misslin R (1993): Some critical determinants of the behaviour of rats in the elevated plus-maze. Behav Proc 29:37-48
Griebel G, Rodgers RJ, Perrault G, Sanger DJ (1997): Risk assessment behaviour: evaluation of utility in the study of 5-HT-related drugs in the rat elevated plus-maze test. Pharmacol Biochem Behav 57:817-827

Hascoet M, Bourin M, Colombel MC, Fiocco AJ, Baker GB (2000): Anxiolytic-like effects of antidepressants after acute administration in a four-plate test in mice. Pharmacol Biochem Behav 65:339-344

Hogg S (1996): A review of the validity and variability of the elevated plus-maze as an animal model of anxiety. Pharmacol Biochem Behav 54:21-30

Koks S, Beljajev S, Koovit I, Abramov U, Bourin M, Vasar E (2001): 8-OH-DPAT, but not deramciclane, antagonizes the anxiogenic-like action of paroxetine in an elevated plus-maze. Psychopharmacology (Berl) 153:365-372

Kramer MS, Cutler N, Feighner J, Shrivastava R, Carman J, Sramek JJ, Reines SA, Liu G, Snavely D, Wyatt-Knowles E, Hale JJ, Mills SG, MacCoss M, Swain CJ, Harrison T, Hill RG, Hefti F, Scolnick EM, Cascieri MA, Chicchi GG, Sadowski S, Williams AR, Hewson L, Smith D, Rupniak NMJ (1998): Distinct mechanism for antidepressant activity by blockade of central substance $\mathrm{P}$ receptors. Science 281:1640-1645

Kurt M, Arik AC, Celik S (2000): The effects of sertraline and fluoxetine on anxiety in the elevated plus-maze test in mice. J Basic Clin Physiol Pharmacol 11:173-180

Lapin IP (1993): Anxiogenic effect of phenylethylamine and amphetamine in the elevated plus-maze in mice and its attenuation by ethanol. Pharmacol Biochem Behav 44:241-243

Lee CC, Rodgers RR (1991): Effects of buspirone on antinociceptive and behaviourial responses to the elevated plusmaze in mice. Behav Pharmacol 2:491-496

Liggett SB (1992): Functional properties of the rat and human beta 3-adrenergic receptors: differential agonist activation of recombinant receptors in Chinese hamster ovary cells. Mol Pharmacol 42:634-637

Lightowler S, Kennett GA, Williamson IJ, Blackburn TP, Tulloch IF (1994): Anxiolytic-like effect of paroxetine in a rat social interaction test. Pharmacol Biochem Behav 49:281-285

Limberger N, Deicher R, Starke K (1991): Species differences in presynaptic serotonin autoreceptors: mainly 5-HT1B but possibly in addition 5-HT1D in the rat, 5-HT1D in the rabbit and guinea-pig brain cortex. Naunyn Schmiedebergs Arch Pharmacol 343:353-364

Lister RG (1987): The use of a plus-maze to measure anxiety in the mouse. Psychopharmacology (Berl) 92:180-185

Molewijk HE, Hartog K, van der Poel AM, Mos J, Olivier B (1996): Reduction of guinea pig pup isolation calls by anxiolytic and antidepressant drugs. Psychopharmacology (Berl) 128:31-38

Molewijk HE, van der Poel AM, Mos J, van der Heyden JA, Olivier B (1995): Conditioned ultrasonic distress vocalizations in adult male rats as a behavioural paradigm for screening anti-panic drugs. Psychopharmacology (Berl) 117:32-40

Moser PC (1989): An evaluation of the elevated plus-maze test using the novel anxiolytic buspirone. Psychopharmacology (Berl) 99:48-53

Nikolaus S, Huston JP, Hasenohrl RU (1999): The neuroki- 
nin-1 receptor antagonist WIN51,708 attenuates the anxiolytic-like effects of ventralpallidal substance $P$ injection. Neuroreport 10:2293-2296

Papp M, Vassout A, Gentsch C (2000): The NK1-receptor antagonist NKP608 has an antidepressant-like effect in the chronic mild stress model of depression in rats. Behav Brain Res 115:19-23

Pellow S, Chopin P, File SE, Briley M (1985): Validation of open:closed arm entries in an elevated plus-maze as a measure of anxiety in the rat. J Neurosci Methods 14:149-167

Pellow S, File SE (1986): Anxiolytic and anxiogenic drug effects on exploratory activity in an elevated plus-maze: a novel test of anxiety in the rat. Pharmacol Biochem Behav 24:525-529

Podhorna J, Brown RE (2000): Flibanserin has anxiolytic effects without locomotor side effects in the infant rat ultrasonic vocalization model of anxiety. Br J Pharmacol 130:739-746

Rodgers RJ (1997): Animal models of 'anxiety': where next? Behav Pharmacol 8:477-504

Rodgers RJ, Cole JC, Aboualfa K, Stephenson LH (1995): Ethopharmacological analysis of the effects of putative 'anxiogenic' agents in the mouse elevated plus-maze. Pharmacol Biochem Behav 52:805-813

Rodgers RJ, Johnson NJ (1995): Factor analysis of spatiotemporal and ethological measures in the murine elevated plus-maze test of anxiety. Pharmacol Biochem Behav 52:297-303

Routtenberg A, Kramis RC (1967): "Foot-stomping" in the gerbil: Rewarding brain stimulation, sexual behavior, and foot shock. Nature 214:173-174

Rupniak NM, Williams AR (1994): Differential inhibition of foot tapping and chromodacryorrhoea in gerbils by CNS penetrant and non-penetrant tachykinin NK1 receptor antagonists. Eur J Pharmacol 265:179-183

Rupniak NMJ, Carlson EC, Harrison T, Oates B, Seward E, Owen S, de Felipe C, Hunt S, Wheeldon A (2000): Pharmacological blockade or genetic deletion of substance $P$ (NK1) receptors attenuates neonatal vocalisation in guinea pigs and mice. Neuropharmacology 39:1413-1421
Santarelli L, Gobbi G, Debs PC, Sibille EL, Blier P, Hen R, Heath MJS (2001): Genetic and pharmacological disruption of neurokinin 1 receptor function decreases anxiety-related behaviors and increases serotonin function. Proc Natl Acad Sci 98:1912-1917

Saria A (1999): The tachykinin NK1 receptor in the brain: pharmacology and putative functions. Eur J Pharmacol 375:51-60

Schatzberg AF (2000): New indications for antidepressants. J Clin Psychiatry 61(Suppl 11):9-17

Schreiber R, Melon C, De Vry J (1998): The role of 5-HT receptor subtypes in the anxiolytic effects of selective serotonin reuptake inhibitors in the rat ultrasonic vocalization test. Psychopharmacology (Berl) 135:383-391

Silva MT, Alves CR, Santarem EM (1999): Anxiogenic-like effect of acute and chronic fluoxetine on rats tested on the elevated plus-maze. Braz J Med Biol Res 32: 333-339

Silva RC, Brandao ML (2000): Acute and chronic effects of gepirone and fluoxetine in rats tested in the elevated plus-maze: an ethological analysis. Pharmacol Biochem Behav 65:209-216

Taylor KM, Snyder SH (1970): Amphetamine: Differentiation by $\mathrm{d}$ - and 1-isomers of behavior involving brain norepinephrine or dopamine. Science 168:1487-1489

Teixeira RM, Santos AR, Ribeiro SJ, Calixto JB, Rae GA, De Lima TC (1996): Effects of central administration of tachykinin receptor agonists and antagonists on plusmaze behavior in mice. Eur J Pharmacol 311:7-14

Varty GB, Morgan CA, Cohen-Williams M, Coffin VL (2000): Pharmacological validation of a novel gerbil elevated plusmaze: Effects of neurokinin NK1 receptor antagonists. Abstracts of the Society for Neuroscience 26:659.12

Vassout A, Veenstra S, Hauser K, Ofner S, Brugger F, Schilling W, Gentsch C (2000): NKP608: a selective NK-1 receptor antagonist with anxiolytic-like effects in the social interaction and social exploration test in rats. Regul Pept 96:7-16

Zohar J, Westenberg HG (2000): Anxiety disorders: a review of tricyclic antidepressants and selective serotonin reuptake inhibitors. Acta Psychiatr Scand (Suppl 403):39-49 